\title{
Preparation and characterization of modified bentonite nano composites for phosphorus removal
}

\author{
Ghadeer Al-Khayyat ${ }^{1,{ }^{*}}$, Karin Schitzenhofer ${ }^{2}$, and Abdallah Shanableh ${ }^{3}$ \\ ${ }^{1}$ Departement of Civil and Environmental Engineering, University of Sharjah, Sharjah, UAE \\ ${ }^{2}$ Institute of Sanitary Engineering and Water Pollution Control, University of Natural Resources and \\ Life Sciences, Vienna, Austria \\ ${ }^{3}$ Research Institute of Sciences and Engineering, University of Sharjah, Sharjah, UAE
}

\begin{abstract}
Due to the restrictions of phosphorus uptake in commonly applied treatment systems such as biological treatment and precipitation, it has been focused to find improved removal technologies. The application of natural nanomaterials as adsorbents is favorable due to high adsorption capacity, low environmental impact and reasonable cost. Specially modified nanoclay presents an efficient and cheap alternative with good recovery abilities. However, the material has to be characterized in detail to understand its behavior. For the characterization, modified bentonite (BNT) was produced through exchanging the cations naturally bound to the bentonite surface with metal polycations. In this study, solutions containing hydroxy-polycations of aluminum (Al-BNT), iron (Fe-BNT), and a combination of aluminum and iron (Al-Fe-BNT) were used to prepare three samples of BNT for phosphorus adsorption. To obtain BNT in an accurate surface - volume ratio, it has to be grinded and sieved. To gain information on the influence of grinding on particle size of modified BNT, the samples were characterized through X-ray fluorescence (XRF), X-ray powder diffraction (XRD), and scanning electron microscopy (SEM). A clear determnation of particle size using SEM was difficult due to agglomeration of samples as a result of milling process. The need of ultrasonication or another separation method increases the production effort of nanosized modified BNT. As due to the improved surface - volume ratio, BNT with smaller mean particle size is expected to perform better, leading to a higher adsorption capacity and adsorption rate and therefore, this additional effort might pay off.
\end{abstract}

*Corresponding author : U15100751@sharjah.ac.ae 


\section{Introduction}

The United Arab Emirates (UAE) experiences a dramatic increase in population that result in an increase in water demand. The UAE is highly dependent on desalination and purification of the available groundwater resources to help meeting the demand for water. The wastewater treatment plants in the UAE are using conventional systems to treat the wastewater without nitrogen or phosphorus removal [1] and therefore, there is a need for further treatment for the removal of such nutrients.

Phosphorus is an essential nutrient for the growth of organisms which may lead to eutrophication, therefore its removal is a major environmental concern specially when it reaches the surface freshwater bodies [2], [3]. Adsorption methods are widely implemented for phosphorus removal from wastewater because they are cheap, efficient, and allow for recovery of adsorbed phosphorus which can be used as fertilizer [1]. Several natural minerals, commercial products and by-products such as zeolite, bentonite, magnetite, alum sludge, fly ash, red mud, gibbsite and boehmite work as phosphorus adsorbents [4]-[9]. Due to their low cost, intrinsic properties and wide availability, clays are favorable in comparison with the other available adsorbents [1], [10], [11].

Clay particles modified with polycations of aluminum, iron, lanthanum or a combination of them can significantly increase the adsorption capacity. The polycations work as pillars between clay layers and therefore increase the surface area, pore volume and permanent porosity [1], [12]. Recently, nano-materials are attracting the attention of researchers to investigate their ability in the removal of pollutants from wastewater. The smaller size of nano-particles compared to micro-sized particles increases the surface area and therefore enhances the adsorption capacity of material against several contaminants [13], [14]. Reducing the size of the clay particles to the nano-level can significantly enhance their ability as adsorbents due to the extensive surface area in addition to the special charge characterization of the clay material [10]. Several studies were performed for the removal of phosphorus and some other anions from wastewater using iron based nano-particles, zinc oxide nano-particles, magnesium oxide nano-particles, copper oxide nano-particles, carbon nano-tubes, and graphene based nano-particles [15]-[18].

The study herein was focused on synthesis and characterization of nano-sized modified clay adsorbents for the removal of phosphorus from water. The modified bentonite adsorbents were prepared using solutions containing hydroxy-polycations of aluminum (Al$\mathrm{BNT}$ ), iron (Fe-BNT), and mixtures of aluminum and iron (Al-Fe-BNT). The nano-sized level of particles was reached through ball milling and the samples were characterized through x-ray fluorescence (XRF), x-ray powder diffraction (XRD), and scanning electron microscopy (SEM).

\section{Materials and methods}

The bentonite particles used in this study are mostly containing sodium (Na-montmorillonite) and it was used in previous study [1]. The bentonite was obtained from a local supplier in Dubai city, United Arab Emirates (Poudrszan Industrial and Mineral Group). The bentonite swell index was observed to be $20 \mathrm{ml} / \mathrm{g}$ which is an indication of highly expansive bentonite [1]. The modified bentonite adsorbents were prepared based on previously documented methods [1], [12], [19]. The bentonite was prepared with three types of stock solutions and two types of pillaring solutions (Table 1) to obtain three types of modified bentonite possessing different $\mathrm{Al} / \mathrm{Fe}$ ratios. The stock solutions consisted of 1 ) $1 \mathrm{~mol} / \mathrm{L}$ sodium carbonate through dissolving $105.99 \mathrm{~g}$ of dry sodium carbonate in $1 \mathrm{~L}$ of distilled water, 2) $0.5 \mathrm{~mol} / \mathrm{L}$ aluminium chloride through dissolving $120.7 \mathrm{~g}$ of aluminium chloride 
$\left(\mathrm{AlCl}_{3} .6 \mathrm{H}_{2} \mathrm{O}\right)$ in $1 \mathrm{~L}$ of distilled water, and 3) $0.2 \mathrm{~mol} / \mathrm{L}$ iron chloride through dissolving $54.1 \mathrm{~g}$ iron chloride $\left(\mathrm{FeCl}_{3} .6 \mathrm{H}_{2} \mathrm{O}\right)$ in $1 \mathrm{~L}$ of distilled water. The $\mathrm{Al}$ pillaring solution (Solution A) was obtained by adding $300 \mathrm{~mL}$ of stock solution 1 as drops into $500 \mathrm{~mL}$ of stock solution 2 to reach a final ratio of $[\mathrm{OH}] /[\mathrm{Al}]=2.4$. The procedure was conducted with a magnetic stirrer at $60{ }^{\circ} \mathrm{C}$ and then the solution was aged for a week. The Fe pillaring solution (Solution B) was prepared by slowly adding $100 \mathrm{~mL}$ of stock solution 1 to $500 \mathrm{~mL}$ of stock solution 3 to reach a ratio of $[\mathrm{OH}] /[\mathrm{Fe}]=2$. Similarly, the procedure was conducted with a magnetic stirrer at $60{ }^{\circ} \mathrm{C}$ and the solution was aged for a week.

Table 1. Preparation conditions of BNT adsorbents [1].

\begin{tabular}{|c|c|c|c|c|c|}
\hline $\begin{array}{l}\text { Bentonite } \\
\text { sample }\end{array}$ & $\begin{array}{c}\text { Bentonite } \\
\text { (g) }\end{array}$ & $\begin{array}{c}\text { Distilled } \\
\text { Water }(\mathrm{mL})\end{array}$ & $\begin{array}{c}\text { Solution } \\
\text { A (mL) }\end{array}$ & $\begin{array}{c}\text { Solution } \\
\text { B (mL) }\end{array}$ & $\begin{array}{c}\text { Ratio mmol (Al } \\
+\mathrm{Fe}) / \mathrm{g} \text { BNT }\end{array}$ \\
\hline Blank BNT & 10 & 1000 & - & - & - \\
\hline $\mathrm{Al}-\mathrm{BNT}_{2.4}$ & 10 & 745 & 255 & - & 8 \\
\hline $\mathrm{Fe}_{-\mathrm{BNT}_{2}}$ & 10 & 520 & - & 480 & 8 \\
\hline $\mathrm{Al}_{4}-\mathrm{Fe}_{4}-\mathrm{BNT}$ & 10 & 632 & 128 & 240 & 8 \\
\hline \multicolumn{6}{|c|}{$\begin{array}{l}\text { Annotations: Solution A was prepared by mixing } 300 \mathrm{~mL} \text { of } 1.0 \mathrm{M} \mathrm{Na}_{2} \mathrm{CO}_{3} \text { with } 500 \mathrm{~mL} \text { of } 0.5 \mathrm{M} \\
\mathrm{AlCl}_{3} .6 \mathrm{H}_{2} \mathrm{O} \text {; Solution B was prepared by mixing } 100 \mathrm{~mL} \text { of } 1.0 \mathrm{M} \mathrm{Na}_{2} \mathrm{CO}_{3} \text { with } 500 \mathrm{~mL} \text { of } 0.2 \\
\qquad \mathrm{M} \mathrm{FeCl}_{3} .6 \mathrm{H}_{2} \mathrm{O} .\end{array}$} \\
\hline
\end{tabular}

All clay preparations were produced at a final volume of $1 \mathrm{~L}$. After several washings with distilled water to get rid of chloride in the supernatant which was tested by silver nitrate, the clay was separated by filtration and dried at $105^{\circ} \mathrm{C}$ for 24 hours. The dried clay was grinded for varying time intervals to obtain different sizes in micro and nano levels. For getting micro size samples, the original bentonite was grinded and sieved, and a size of $75 \mu \mathrm{m}$ to $150 \mu \mathrm{m}$ was obtained. Then, the particels size were further reduced through ball milling method. Ball milling is a widely-used technique for particle size reduction but the problem of agglomeration usually occures whenever it's applied in a dry powder form. A combination of ball milling and ultrasonication can effectively reduce the particle size and minimize agglomeration. The particles were grinded in ball milling machine (Type PM100) using Teflon containers of size $25 \mathrm{ml}$ with eight Teflon balls of $12 \mathrm{~mm}$ diameter for 1 hour, 2 hours, and 3 hours under dry conditions at $450 \mathrm{rpm}$. The particles were then characterized through $\mathrm{x}$-ray powder diffraction (XRD) and scanning electron microscopy (SEM) to ensure reaching the nano-size level and recording the particles sizes.

\section{Results and discussion}

A knowledge of the material properties and particle characterization is important specially when the material is to be implemented in an application. In this research, the bentonite adsorbents were characterized by XRF, XRD, and SEM. XRF was performed using (HORIBA, XGT-7200V) with a beam diameter of $1.2 \mathrm{~mm}$ and for a duration of 200 seconds. Herein, the chemical composition of the modified bentonite samples was determined through XRF. Table 2 and Fig. 1 below show XRF results with silicone as the most dominant element in bentonite.

Table 2. Chemical composition results of bentonite samples using XRF.

\begin{tabular}{|c|c|c|c|c|c|c|c|c|c|}
\hline \multirow{2}{*}{$\begin{array}{c}\text { Bentonite } \\
\text { sample }\end{array}$} & \multicolumn{10}{|c|}{ Element } \\
\cline { 2 - 11 } & $\mathrm{Mg}$ & $\mathrm{Al}$ & $\mathrm{Si}$ & $\mathrm{S}$ & $\mathrm{Cl}$ & $\mathrm{K}$ & $\mathrm{Ca}$ & $\mathrm{Ti}$ & $\mathrm{Fe}$ \\
\hline $\mathrm{Fe}-\mathrm{BNT}$ & 2.54 & 5.68 & 30.31 & 0.16 & 2.45 & 0.22 & 0.54 & 0.20 & 57.89 \\
\hline $\mathrm{Al}-\mathrm{BNT}$ & 3.71 & 21.43 & 61.40 & 0.48 & 0.29 & 0.83 & 2.27 & 0.79 & 8.80 \\
\hline $\mathrm{Al}$-Fe4-BNT & 3.24 & 11.29 & 42.80 & 0.16 & 0.90 & 0.42 & 1.26 & 0.40 & 39.52 \\
\hline
\end{tabular}




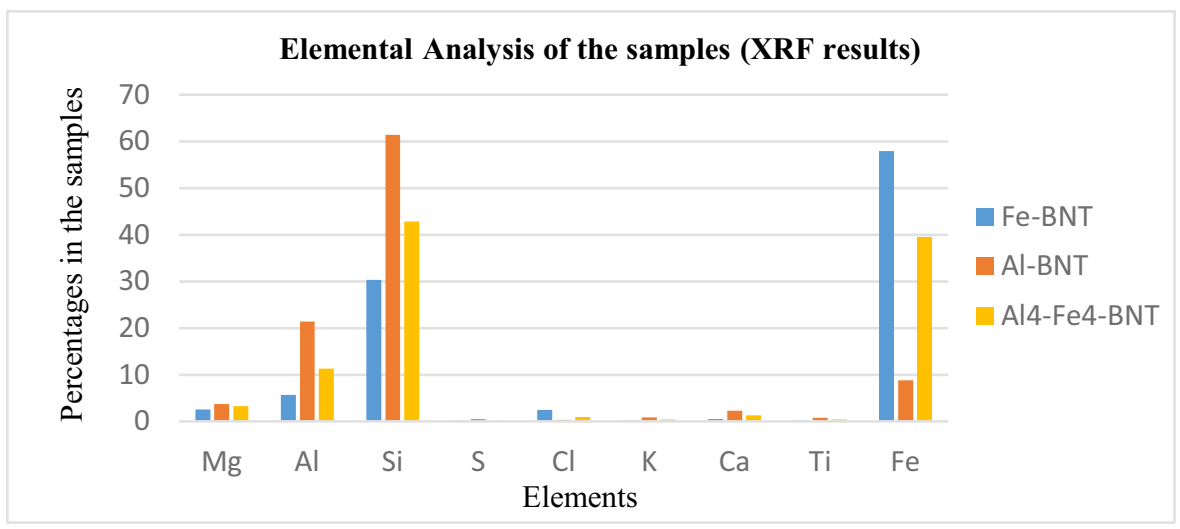

Fig. 1. Percentages of the chemical elements in each of the three modified bentonite samples.

The 1, 2 and 3 hours' ball milled samples of BNT, Al-BNT, Fe-BNT, and $\mathrm{Al}_{4}-\mathrm{Fe}_{4}-\mathrm{BNT}$ were analyzed through X-ray powder diffraction (XRD) and shown in Fig. 2 below. XRD test was performed using (Bruker D8 advance) with $40 \mathrm{kv}$ applied voltage and $50 \mathrm{~mA}$ current. The step size was 0.2 degree with 0.2 seconds per step for angles between 5 and 85 degrees. XRD test was carried to ensure that structure of particles was not damaged with modifying original bentonite or with reducing particle size. It was found that as the particle size decreased, the count value increased. Also, chemical composition of the different minerals presented in the samples were determined and shown in Fig. 3 below. Cristobalite, quartz, kyanite, dolomite, and aerinite were the dominent minerals in bentonite samples.
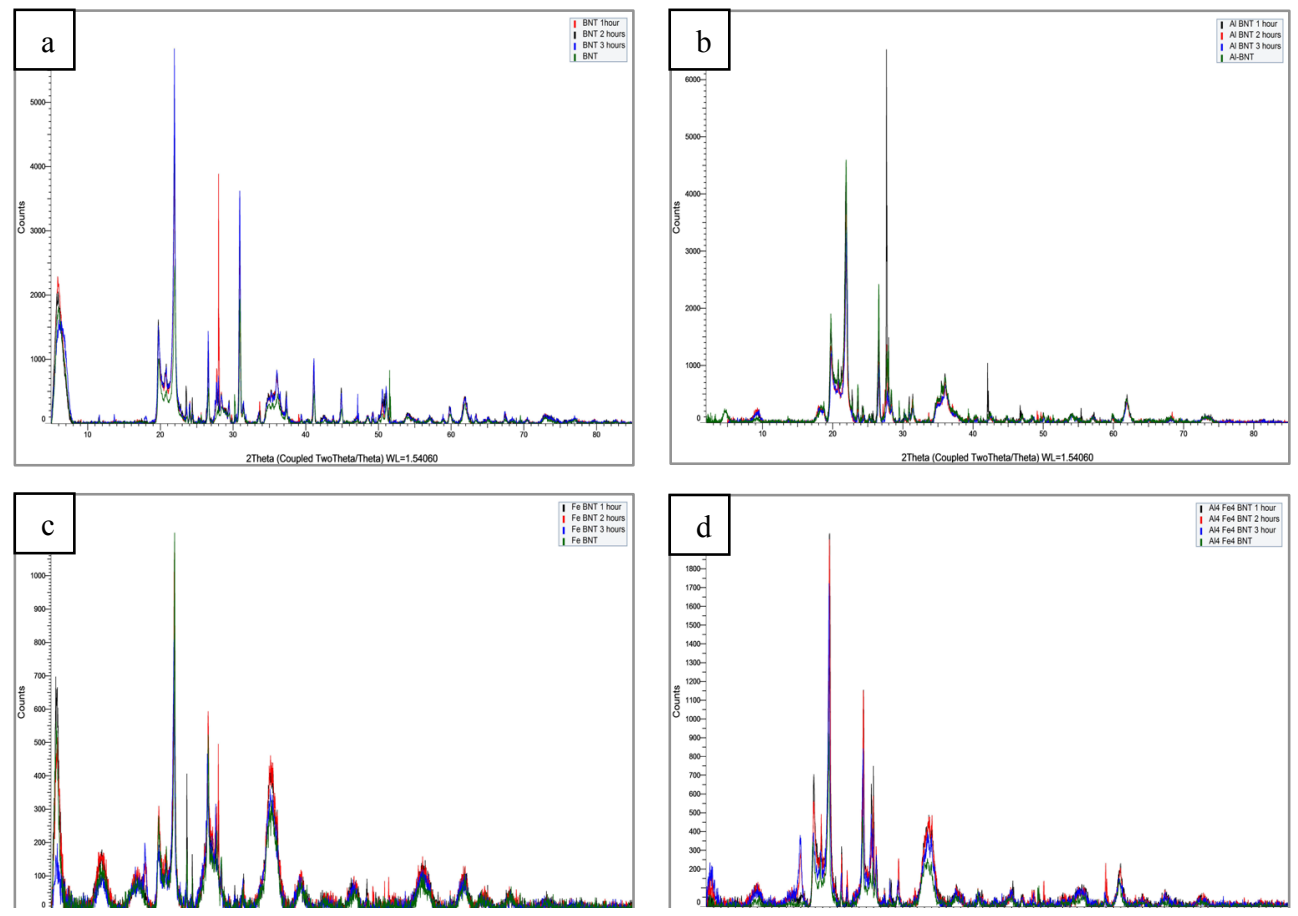

Fig. 2. XRD results of 1, 2, and 3 hours' ball milled samples. (a) BNT sample, (b) Al-BNT sample, (c) Fe-BNT sample, and (d) $\mathrm{Al}_{4}-\mathrm{Fe}_{4}-\mathrm{BNT}$ sample. 

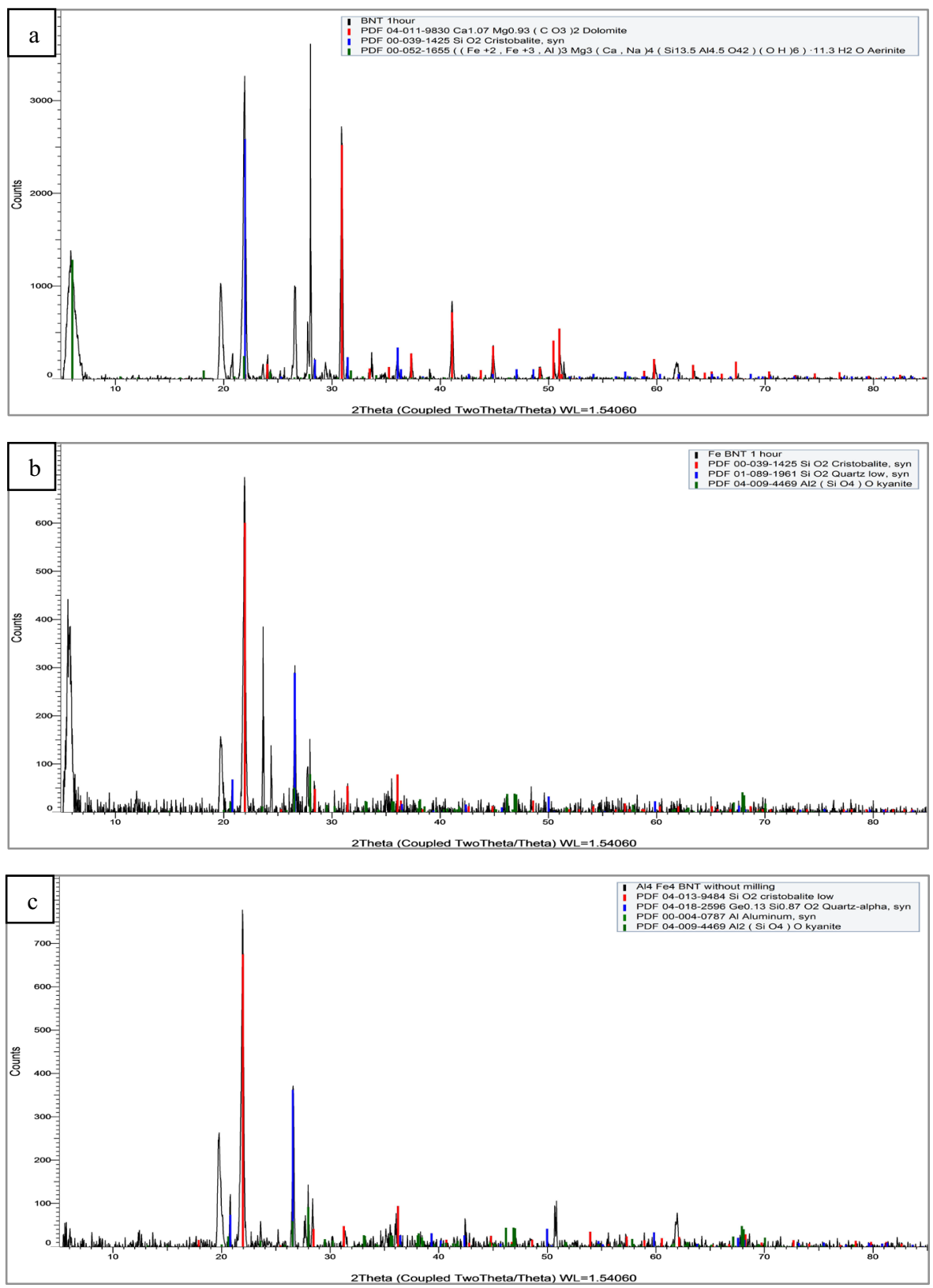

Fig. 3. XRD results for chemical composition of minerals in the samples. (a) BNT sample, (b) FeBNT sample, and (c) $\mathrm{Al}_{4}-\mathrm{Fe}_{4}-\mathrm{BNT}$ sample.

Prior to characterization of bentonite samples through scanning electron microscopy (SEM) and to reduce particles agglomeration, the particles were dispersed in an ultrasonication path at $24^{\circ} \mathrm{C}$ for approximately 1 hour. Then, the samples were coated with carbon layer of $20 \mathrm{~nm}$ thickness for a duration of 2 minutes using carbon evaborater device (Quorum-CA7625). SEM was perfromed to determine the particle size of bentonite samples using (Tescan, environmental SEM, source: LaB 6) with 30 kv voltage. Fig. 4 below shows 
SEM results after 1 hour of ball milling. Furtehr sonication is needed to minimize the presence of agglomerartion as shown in SEM images (Fig. 4).
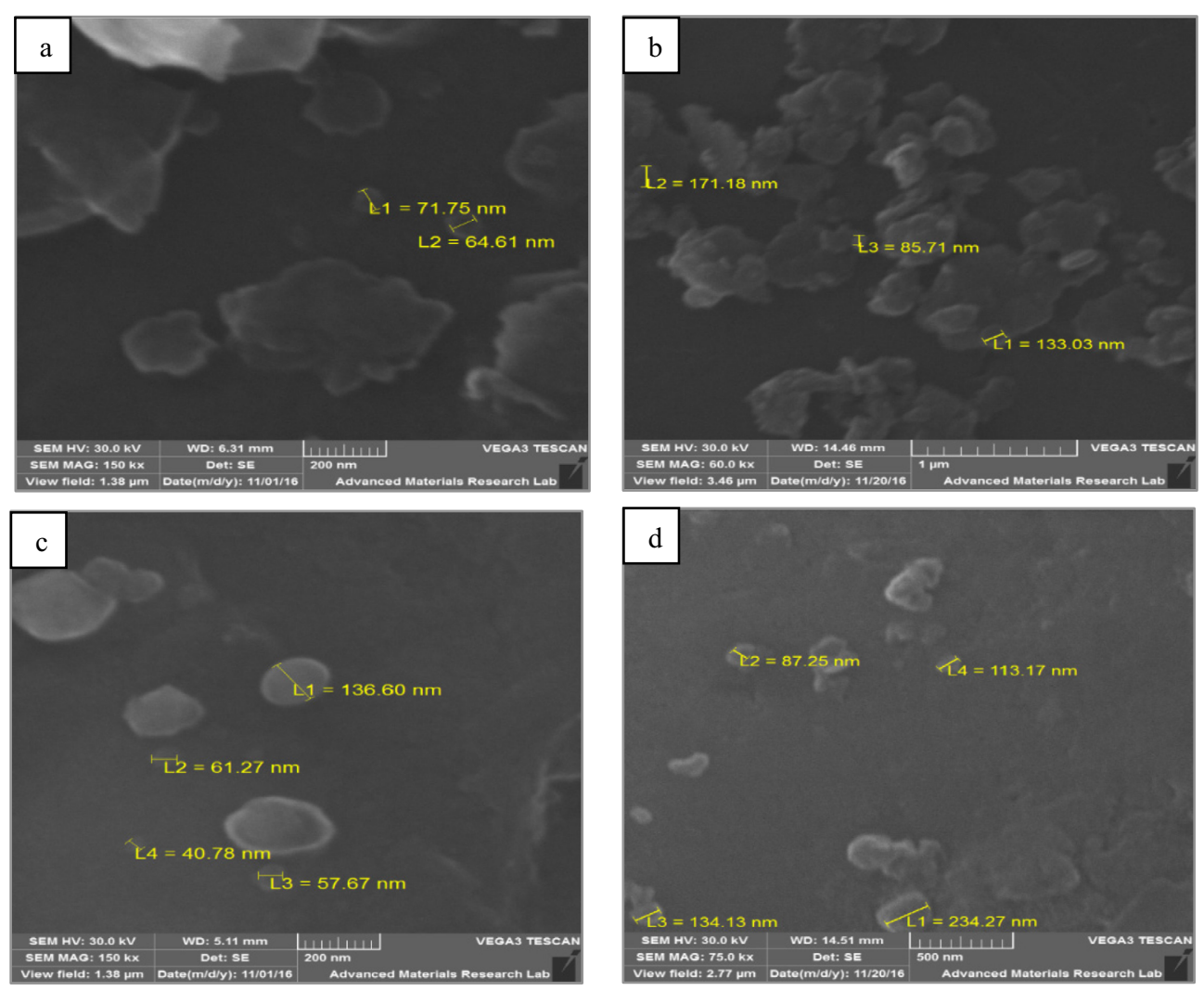

Fig. 4. SEM results of 1 hour ball milled bentonite samples. (a) BNT sample, (b) Al-BNT sample, (c) Fe-BNT sample, and (d) $\mathrm{Al}_{4}-\mathrm{Fe}_{4}-\mathrm{BNT}$ sample.

To study the impact of sample particle size against its adsorption capacity for phosphorus with time, an adsorption kinetics experiment was performed. A stock solution of phosphates ( $50 \mathrm{mg} / 1$ of phosphorous) was prepared by dissolving $0.221 \mathrm{gm}$ of $\mathrm{KH}_{2} \mathrm{PO}_{4}$, dried at $120^{\circ} \mathrm{C}$ for 2 hours in 1 liter distilled water. The size of the phosphorus stock solution was $50 \mathrm{ml}$, and the amount of adsorbent added to the solution each time was $0.1 \mathrm{~g}$. The sample $\mathrm{pH}$ was adjusted to 5 by using $\mathrm{HCL}$ or $\mathrm{NaOH}$, as it's the most appropriate value for phosphorus adsorption. The adsorption experiment was performed with initial concentration of $25 \mathrm{mg}$ $\mathrm{P} / 1$. The test was carried on magnetic stirrers at $200 \mathrm{rpm}$ and phosphorus concentration was measured at intermediate intervals $(15,30,45,60,90,120,180$, minutes $\ldots$ etc.) and up to 5 hours. For adsorbent separation from the solution, a centrifugation technique was applied at 6,000 rpm for approximately 20 minutes. The $\mathrm{PO}_{4}-\mathrm{P}$ concentration was measured according to the ascorbic acid standard method with a UV-Vis spectrophotometer.

Table 3 and Fig. 5 below show the results of adsorption experiment using bentonite samples. The results showed significant increase in adsorption capacity of modified bentonite compared to the blank samples. Fe-BNT in the micro size level reached an adsorption capacity of $9.8 \mathrm{mg} \mathrm{P} / 1$ which is the highest among other adsorbents. Adsorption capacities of samples in the nano size level were not as expected and that's due to the agglomeration of 
the particles before and during the experiment. Agglomerated particles reduced the surface area for phosphorus to be adsorbed on bentonite samples.

Table 3. Adsorption capacity of modified bentonite against phosphorus.

\begin{tabular}{|c|c|c|c|c|c|c|c|c|c|c|}
\hline \multirow{2}{*}{$\begin{array}{c}\text { Bentonite } \\
\text { sample }\end{array}$} & \multirow{2}{*}{ Size Level } & \multicolumn{8}{|c|}{ Adsorption Capacity (mg P / BNT) } \\
\cline { 3 - 13 } & & 15 & 30 & 45 & 60 & 90 & 120 & 180 & 240 & 300 \\
\hline \multirow{2}{*}{$\mathrm{BNT}$} & Micro & 0 & 0 & 0.2 & 0 & 0 & 0 & 0.2 & 0 & 0 \\
\cline { 2 - 13 } & Nano & 0.4 & 0.2 & 0.4 & 0.2 & 0.2 & 0.2 & 0.4 & 0.2 & 0.2 \\
\hline \multirow{2}{*}{$\mathrm{Al}-\mathrm{BNT}$} & Micro & 1.4 & 1.4 & 1.4 & 1.8 & 2.6 & 4.0 & 1.0 & 3.0 & 5.4 \\
\cline { 2 - 12 } & Nano & 0.8 & 0.8 & 1.8 & 2.4 & 1.8 & 3.4 & 0.6 & 2.2 & 4.8 \\
\hline \multirow{2}{*}{$\mathrm{Fe}-\mathrm{BNT}$} & Micro & 4.2 & 7 & 6.8 & 7.4 & 7.6 & 8 & 8.6 & 8.2 & 9.8 \\
\cline { 2 - 12 } & Nano & 4.6 & 5.2 & 5.6 & 6.2 & 5.4 & 5.6 & 7.2 & 7.8 & 7.8 \\
\hline \multirow{2}{*}{$\mathrm{Al}_{4}-\mathrm{Fe}_{4}-\mathrm{BNT}$} & Micro & 0.8 & 3.4 & 3.2 & 5.4 & 4.4 & 4.6 & 4.2 & 3.6 & 7.8 \\
\cline { 2 - 11 } & Nano & 2.4 & 3.4 & 3.6 & 3.8 & 3.8 & 5.6 & 5.4 & 5.4 & 6.2 \\
\hline
\end{tabular}

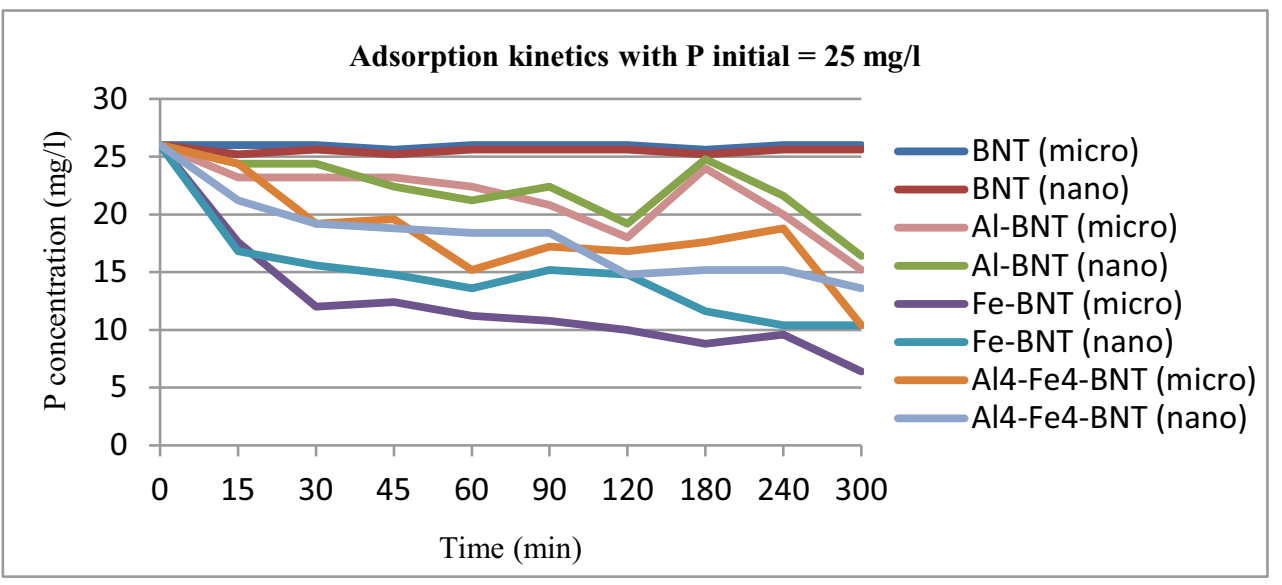

Fig. 5. Adsorption kinetics results of modified bentonite samples against phosphorus.

\section{Conclusion}

This study was performed for the synthesis and characterization of modified nano bentonite samples for phosphorus adsorption. Samples characterization was done through XRD, XRF, and SEM tests. Size of bentonite particles was around $70 \mathrm{~nm}$ after 1 hour of ball milling. The adsorption kinetics experiment showed that modified bentonite samples in micro size level performed better than nano size level. Agglomeration of nano bentonite samples prevented maximum adsorption of phosphorus by bentonite particles. Further treatment for nano samples should be considered before running phosphorus adsorption experiment.

Support from Advanced Materials Research Lab and Environmental Engineering Lab at the University of Sharjah are both acknowledged. 


\section{References}

1. A. M. Shanableh and M. M. Elsergany, "Removal of phosphate from water using six Al-, Fe-, and Al-Fe-modified bentonite adsorbents.," J. Environ. Sci. Health. A. Tox. Hazard. Subst. Environ. Eng., vol. 48, no. 2, pp. 223-31. (2013)

2. L. Zeng, X. Li, and J. Liu, "Adsorptive removal of phosphate from aqueous solutions using iron oxide tailings," Water Res., vol. 38, pp. 1318-1326. (2004)

3. A. Genz, A. Kornmu, and M. Jekel, "Advanced phosphorus removal from membrane filtrates by adsorption on activated aluminium oxide and granulated ferric hydroxide," vol. 38, pp. 3523-3530. (2004)

4. E. W. SHIN, J. S. HAN, M. JANG, S.-H. MIN, J. K. PARK, and R. M. ROWELL, "Phosphate Adsorption on Aluminum-Impregnated Mesoporous Silicates : Surface Structure and Behavior of Adsorbents," Environ. Sci. Technol., vol. 38, no. 3, pp. 912-917. (2004)

5. E. López, B. Soto, M. Arias, A. Núñez, D. Rubinos, and M. T. Barral, “Adsorbent properties of red mud and its use for wastewater treatment," Water Res., vol. 32, no. 4, pp. 1314-1322. (1998)

6. J. Edzwald, "Phosphate adsorption reactions with clay minerals," Environ. Sci. Technol., vol. 10, no. 5, pp. 485-490. (1976)

7. E. Oguz, "Removal of phosphate from aqueous solution with blast furnace slag," $J$. Hazard. Mater., vol. 114, pp. 131-137. (2004)

8. E. Oguz, "Thermodynamic and kinetic investigations of PO3-4 adsorption on blast furnace slag.," J. Colloid Interface Sci., vol. 281, no. 1, pp. 62-7. (2005)

9. J. Chen, H. Kong, D. Wu, X. Chen, D. Zhang, and Z. Sun, "Phosphate immobilization from aqueous solution by fly ashes in relation to their composition," J. Hazard. Mater., vol. 139, pp. 293-300. (2007)

10. G. Yuan and L. Wu, "Allophane nanoclay for the removal of phosphorus in water and wastewater," Sci. Technol. Adv. Mater., vol. 8, no. 1-2, pp. 60-62. (2007)

11. M. L. Schlegel, A. Manceau, D. Chateigner, and L. Charlet, "Sorption of Metal Ions on Clay Minerals: I. Polarized EXAFS Evidence for the Adsorption of Co on the Edges of Hectorite Particles," J. Colloid Interface Sci., vol. 215, pp. 140-158. (1999)

12. S. Tian, P. Jiang, P. Ning, and Y. Su, "Enhanced adsorption removal of phosphate from water by mixed lanthanum / aluminum pillared montmorillonite," Chem. Eng. $J$. , vol. 151, pp. 141-148. (2009)

13. M. Anjum, R. Miandad, M. Waqas, F. Gehany, and M. A. Barakat, "Remediation of wastewater using various nano- materials," Arab. J. Chem. (2016)

14. S. P. Gubin, Y. A. Koksharov, G. B. Khomutov, and G. Y. Yurkov, "Magnetic nanoparticles : preparation, structure and properties," (2005)

15. S. Mahdavi and D. Akhzari, "The removal of phosphate from aqueous solutions using two nano-structures: Copper oxide and carbon tubes," Clean Technol. Environ. Policy, vol. 18, no. 3, pp. 817-827. (2016)

16. B. D. Martin, L. De Kock, T. Stephenson, S. A. Parsons, and B. Jefferson, "The impact of contactor scale on a ferric nanoparticle adsorbent process for the removal of phosphorus from municipal wastewater," Chem. Eng. J., vol. 215-216, pp. 209215. (2013)

17. B. D. Martin, "Removal and recovery of phosphorus from municipal wastewaters using a ferric nanoparticle adsorbent,". (2010)

18. T. Shahwan, C., Üzüm, A. E. Eroğlu, and I. Lieberwirth, "Synthesis and characterization of bentonite/iron nanoparticles and their application as adsorbent of cobalt ions," Appl. Clay Sci., vol. 47, no. 3-4, pp. 257-262. (2010)

19. L. Zhu and R. Zhu, "Simultaneous sorption of organic compounds and phosphate to inorganic - organic bentonites from water," vol. 54, pp. 71-76. (2007) 